\title{
The Comparison of The Efficacy of Photobiomodulation and Ultrasound in the Treatment of Chronic Non-specific Neck Pain: A Randomized Single-Blind Controlled Trial
}

\author{
Rahele Kenareh $^{1}{ }^{\circledR}$, Seyyed Jalil Mirmohammadi ${ }^{\circledR}{ }^{\circledR}$, Amidoddine Khatibi $^{3}{ }^{\circledR}$, Farimah Shamsi ${ }^{4}{ }^{\circledR}$, Amir \\ Houshang Mehrparvar ${ }^{5^{*}(\mathbb{D}}$ \\ ${ }^{1}$ Occupational Health Research Center, School of Public Health, Shahid Sadoughi University of Medical Sciences, Yazd, \\ Iran \\ ${ }^{2}$ Industrial diseases Research Center, Shahid Sadoughi University of Medical Sciences, Yazd, Iran \\ ${ }^{3}$ School of Medicine, Shahid Sadoughi University of Medical Sciences, Yazd, Iran \\ ${ }^{4}$ Abortion Research Center, School of Public Health, Shahid Sadoughi University of Medical Sciences, Yazd, Iran \\ ${ }^{5}$ Industrial Diseases Research Center, Shahid Sadoughi University of Medical Sciences, Yazd, Iran
}

\section{*Correspondence to Amir Houshang Mehrparvar, Occupational Medicine department, Shahid Rahnemoun hospital, Farrokhi ave., Yazd, Iran. \\ Tel: 00983537247111 ; Email: ah.mehrparvar@gmail. com}

Published online May 17, 2021

\section{Introduction}

In recent years, due to advances in technology and computer work and changes in occupational tasks, neck pain has become the second most common cause of musculoskeletal disability after low back pain (LBP)., ${ }^{1,2}$ The long-term and awkward body postures in office workers may lead to back and neck pain and fatigue. ${ }^{3}$ In Iran, musculoskeletal disorders (MSDs) are the most common occupational illness and injury, accounting for $7 \%$ of diseases in the general population and $14 \%$ of patient referrals to physicians. Many factors may contribute to the development of MSDs. These include manual material handling, inappropriate workstations, repetitive movements, and so on. ${ }^{4}$

The incidence of neck pain ranges from $34 \%$ to $54 \%$ in different populations. ${ }^{5,6}$ In many cases, the basic pathophysiology of neck pain is unknown and as a result, it is referred to as non-specific neck pain. Occasionally, neck pain becomes chronic and costs a great deal of time and money to the health system to diagnose and treat it. ${ }^{7}$

The persistence of neck pain for more than 3 months is defined as chronic pain. In $14 \%$ of neck pain cases, chronic pain is experienced and in $5 \%$ of cases, it leads to disability. ${ }^{8}$ Chronic neck pain is responsible for absenteeism and affects patients' quality of life. These patients may need specialized care, and their treatment may impose huge

Please cite this article as follows: Kenareh R, Mirmohammadi SJ, Khatibi A, Shamsi F, Mehrparvar AH. The comparison of the efficacy of photobiomodulation and ultrasound in the treatment of chronic non-specific neck pain: a randomized single-blind controlled trial. J Lasers Med Sci. 2021;12:e20. doi:10.34172/jlms.2021.20 
costs on society. ${ }^{9}$ Therefore, implementing effective ways to treat chronic neck pain is of importance.

Various methods have been used to treat chronic neck pain, including pharmacotherapy and acupuncture, cervical massage, photobiomodulation using low-level laser therapy (LLLT) or high-intensity laser therapy (HILT), physiotherapy, neck-specific strengthening exercises and workplace ergonomic modifications. ${ }^{10-15}$

HILT is a new, non-invasive, painless, and powerful method ${ }^{16}$ with anti-inflammatory and reparative effects. ${ }^{17}$ HILT has therapeutic benefits through photochemical, photothermal, and photomechanical mechanisms, possibly due to its potential for reducing inflammation, enhancing microcirculation, and stimulating immunological proteins and nerve regeneration and secretion of $\beta$-endorphins. ${ }^{18-20}$

Physiotherapy, as another therapeutic method, is a non-invasive procedure used to relieve pain and spasm and improve blood circulation. ${ }^{14}$ One of the modalities of physiotherapy is the use of ultrasound (US). US therapeutic frequencies are between 1 and $3 \mathrm{MHz}$, but the most common frequency used for therapeutic goals is 1 MHz. ${ }^{21}$

Several studies have shown the anti-nociceptive effect of HILT. ${ }^{22-26}$ In the study of Kim et al ${ }^{22}$ and Nazari et al, ${ }^{23}$ HILT was more effective than US treatment in controlling pain in patients with knee osteoarthritis. Other studies have shown a superior effect for HILT than US in controlling pain due to lumbar spine and shoulder disorders, ${ }^{24} \mathrm{LBP},{ }^{25}$ and sub-acromial impingement syndrome. ${ }^{26}$

However, there are some controversies between the studies. For example, Boyraz et al did not find this difference between two methods for the treatment of pain in patients with lumbar disc protrusion ${ }^{27}$ and Kolu et al showed a greater therapeutic effect for physiotherapy than HILT in the treatment of radiculopathy. ${ }^{28}$ One reason for these controversies is probably the differences between study populations and the disorders which have been assessed.

We could not find a study to compare the effect of US and HILT on reducing chronic neck pain. Given the high prevalence of nonspecific chronic neck pain in office workers and lack of definitive and conclusive results in the treatment of this disorder, this study aimed to compare the efficacy of HILT with US in the treatment of chronic nonspecific neck pain.

\section{Materials and Methods}

This study was a single-blind randomized controlled trial (RCT) with a parallel allocation model. The main outcome which was studied was the effect of treatment on the improvement of symptoms and function. All study participants were referred to the university clinic for assessment.

Inclusion criteria were: neck pain lasting at least 6 months, age between 25 and 55 years, more than 1 year of work experience, and working time of at least 35 hours per week. The patients were excluded if they had neck and shoulder skin lesions, pregnancy, history of systemic diseases (neoplasms, diabetes, arthritis \& neuropathies), neck trauma, spinal fracture, known cervical disk disease (confirmed by previous imaging studies), and congenital cervical spine disorders. ${ }^{29}$

\section{Participants}

A total of 60 office workers of Shahid Sadoughi University of Medical Sciences (43 females and 17 males) entered the study considering inclusion and exclusion criteria. The participants were randomly allocated into two groups of 30 individuals based on random digits table: US and HILT groups. To conceal the allocation, the type of intervention was written on a piece of paper and put inside closed envelopes. The sample size was calculated considering the power of $80 \%$ and $\alpha=0.05$ using data from previous studies. ${ }^{13}$ The number of patients in each group increased to 30 in case of possible patient dropout.

\section{Intervention}

All patients in both groups received conventional neck pain treatments, including posture correction and exercise training.

Group 1 (physiotherapy/US): Each patient was treated with an expert physiotherapist for 30 minutes daily for 10 sessions over a two-week period using US methods. ${ }^{26}$ US was performed by a 215P class 1 device (Novin Medical Engineering Co., Iran). Its maximum output was $3 \mathrm{~W}$ and it worked in a frequency range of 1.1-3.4 MHz. The used frequency in this study was $2 \mathrm{MHz}$.

Group 2 (photobiomodulation using HILT): Each patient was treated with a gallium-aluminum-arsenide laser system (Class IV) for 9 minutes daily for a total of 10 sessions over a two-week period. ${ }^{16}$ HILT was performed by a VELAS II-15B device (Wuhan Gigaa Optronics Technology, China). The power, frequency and dosage of the device were set at $10 \mathrm{~W}, 25 \mathrm{~Hz}$ and $15 \mathrm{~J} / \mathrm{cm}^{2}$ respectively for 3 minutes which was continued for 6 minutes with 7 $\mathrm{W}$ power and $100 \mathrm{~J} / \mathrm{cm}^{2}$ dosage.

\section{Outcome Measurement}

Initially, a questionnaire including demographic data and data about neck pain was completed for all participants. Visual analogue scale (VAS), Neck Disability Index (NDI), Neck Pain and Disability Scale (NPDS), and Bournemouth Questionnaire for Neck Pain (BQN) were also completed for them. ${ }^{30}$ The questionnaires were completed by a researcher blinded to the study groups. Then all participants were examined by a physical medicine specialist blinded to the study. All questionnaires were completed again immediately and 2 weeks after the intervention.

The VAS is a $10 \mathrm{~cm}$ ruler which visually scores pain severity: the least severe pain on the left and the most 
severe pain on the right side. Depending on the pain severity over the past 2 hours, the person makes a mark on the scale and the result is reported from zero to ten as follows: 0-1: no pain, 2-3: low pain, 4-5: great pain, 6-7: very bad pain, 8-9: maximum pain, and 10: unbearable Pain. ${ }^{31}$ BQN is a biopsychosocial scale including questions on pain, disability, and a cognitive model of pain. ${ }^{32}$ In NPDS and BQN questionnaires, pain in the last 48 hours is assessed and the patient continuously scores from 0 to 10 to his/her pain. The NDI questionnaire is a valid criterion which indicates the effect of neck pain on daily activities. In each part, the patient receives a score between 0 and 5.33,34 Figure 1 shows the steps of the study. The data were analyzed by IBM SPSS statistics for windows, version 19 (IBM Corp., Armonk, N.Y., USA) software using the chi-square test, student's $t$ test, multivariate tests, and Fisher's exact test. The level of significance was set at $P<0.05$.

\section{Results}

Sixty patients were enrolled in the study and were randomly allocated into two intervention groups. The ratio of females to males was 2.75 and 2.33 in US and HILT groups respectively, and the difference was not statistically significant $(P=0.77)$. Age, work experience and duration of neck pain were not significantly different between the two groups. Table 1 compares demographic data between the two groups.

The mean scores of VAS and NDI were both significantly higher in the HILT group before the intervention and decreased after the intervention in both groups, but the decrease was significantly higher in the HILT group than the US group. Figure 2 compares the score of VAS and NDI between the two study groups before and after the intervention.

All variables related to the neck pain, its characteristics, its effect on daily and work activities and its severity were significantly higher in the HILT group before the intervention, but these variables significantly improved immediately and two weeks after the intervention in both groups; the effect of HILT on reducing the scores of neck pain variables was significantly higher than US in all variables on both occasions after the intervention

Table 1. Comparison of Demographic Data Between the Two Groups

\begin{tabular}{lccc}
\hline Study Groups & Age $(\mathbf{y})$ & $\begin{array}{c}\text { Work Experience } \\
(\mathbf{y})\end{array}$ & $\begin{array}{c}\text { Duration of Neck Pain } \\
(\mathbf{y})\end{array}$ \\
\hline US & $37.53 \pm 9.52$ & $12.76 \pm 8.60$ & $12.86 \pm 9.54$ \\
HILT & $41.16 \pm 7.85$ & $16.30 \pm 7.06$ & $13.66 \pm 11.14$ \\
$P$ value & 0.11 & 0.08 & 0.76 \\
\hline
\end{tabular}

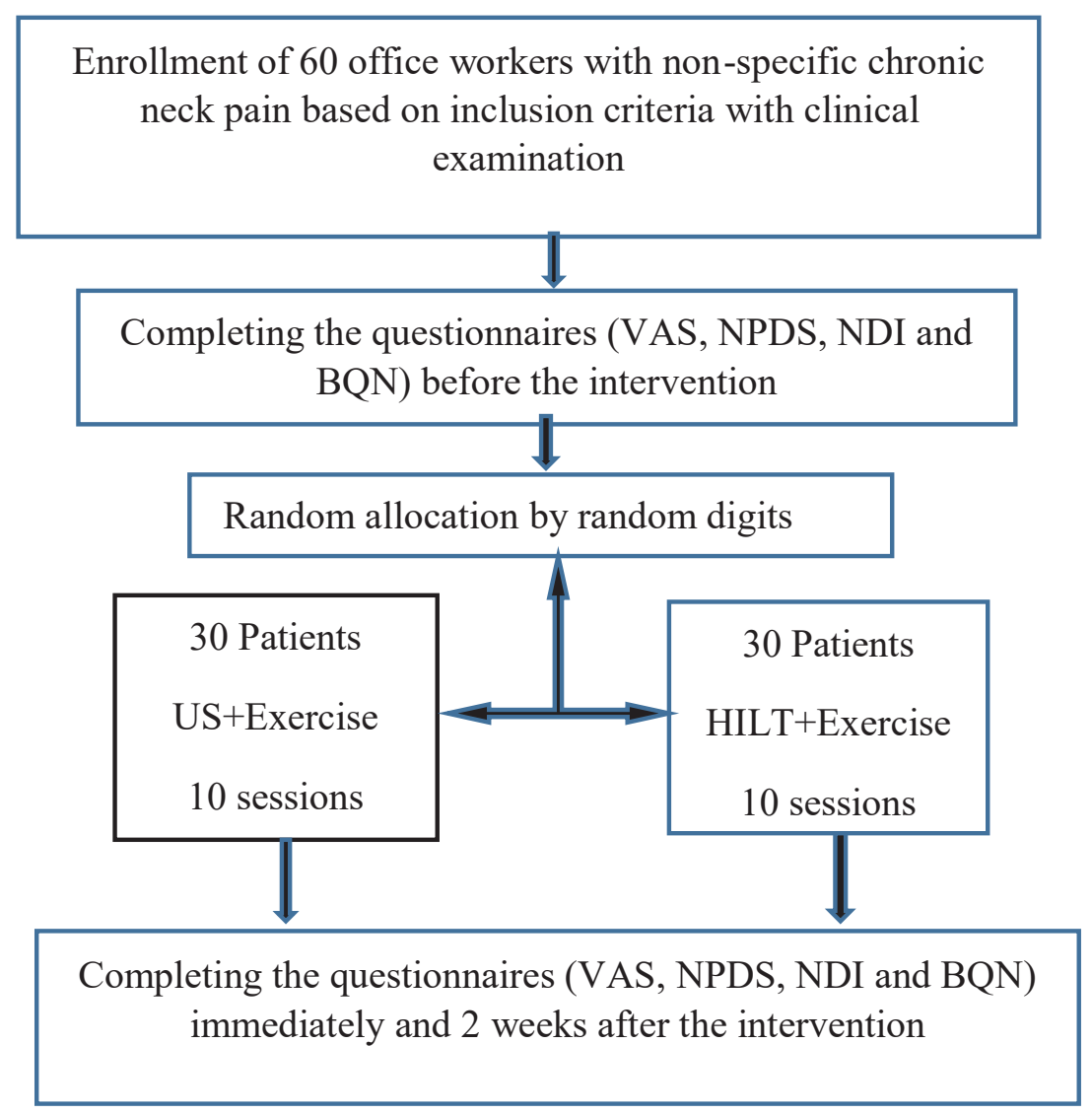

Figure 1. Flow Chart of the Steps of the Study. 


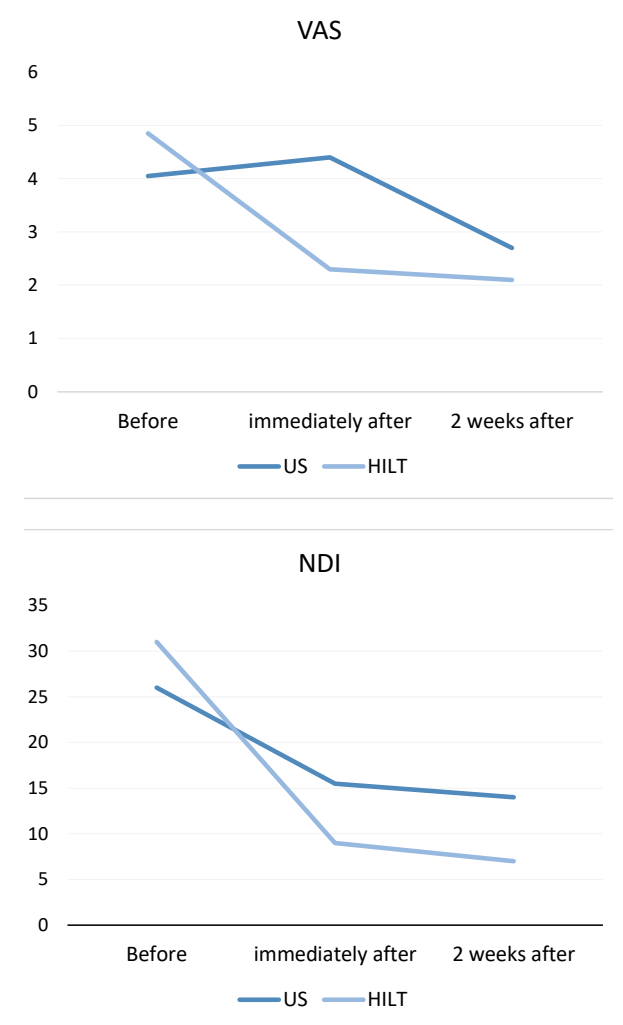

Figure 2. Comparison of Mean Difference of VAS and NDI Scores in Two Study Groups Before and After the Intervention (sloid line: HILT; dashed line: US).

$(P<0.001)$ (mean difference between two occasions after the intervention and before the intervention). Table 2 compares the mean difference of NDPS and BQN scores before the intervention and immediately and two weeks after the intervention.

\section{Discussion}

Chronic non-specific neck pain is considered a common occupational disorder, especially among office workers. The present study compared the therapeutic effect of two different physical modalities in patients diagnosed with chronic non-specific neck pain: HILT and US. The results were obtained after 10 treatment sessions over 2 consecutive weeks. Both methods were effective in reducing patients' complaints and improving their outcome, but the HILT was significantly more effective than the US. We could not find another study on the comparison of the effect of different physical therapy methods on chronic non-specific neck pain so this is probably the first study in this regard.

Among physical modalities, US therapy and laser therapy have shown different results in the treatment of MSDs. ${ }^{35}$ HILT may reduce pain through such mechanisms as affecting the pain stimulus and level of morphine-mimetic substances, ${ }^{36}$ C-fiber transmission, ${ }^{37}$ and augmenting vascular permeability and cell metabolism. ${ }^{38}$ HILT may increase oxidative reactions in the mitochondria, which leads to tissue stimulation. ${ }^{25}$

Several studies have used physical medicine treatment methods in various diseases such as osteoarthritis, lumbar discopathy, radiculopathy and neck pain with different results. Kolu et al assessed the effect of HILT and US with transcutaneous nerve stimulation on the treatment of lumbar radiculopathy and found a more prominent effect for US than HILT, ${ }^{28}$ which was inconsistent with the results of the present study; although we assessed patients with non-specific neck pain, their population consisted of patients with lumbar radiculopathy so the results cannot be compared.

Several studies have found HILT as an effective method for reducing pain in different body areas. In Nazari and colleagues' study on patients with knee osteoarthritis, consistent with the results of the current study, HILT had a more prominent effect on reducing pain and improving function compared to conventional treatment. ${ }^{23}$ Best and colleagues' study on patients with lumbar spine or shoulder disorder showed that both US and HILT reduced the intensity of regional pain, but HILT was more effective, which was consistent with the results of the present study. ${ }^{24}$ Fiore et al also compared the effect of US and HILT on LBP and found a greater pain reduction in the HILT group. ${ }^{25}$

In the present study, most aspects of neck pain were higher in the HILT group at the beginning of the study and before the intervention, and it seems that neck pain was more severe in the participants of this group before the intervention. Although the improvement in pain complaints and other aspects of neck pain and its effect on daily and work activities and cognitive function was significant in both groups, the effect was more prominent in the HILT group on both occasions after the intervention. According to the results, both the raw scores of the variables and the mean differences of the scores related to neck pain were more significantly reduced in the HILT group than the US group. It means that HILT reduced neck pain from a higher level than the US before the intervention to a lower level after the intervention, which shows a very significant effect for this therapeutic modality in comparison to the US. Therefore, the baseline differences between the two groups did not probably affect the outcome because the mean difference in almost all variables was higher in the HILT group.

This study had some limitations including lack of a control group and placebo treatment. The follow-up period in this study was only 2 weeks after the intervention; probably a longer duration of follow-up may show more detailed results on the effect of interventions.

\section{Conclusion}

The results of the present study showed that both photobiomodulation and US reduced chronic nonspecific neck pain and improved functional scales related to neck pain, and the effect of HILT was significantly 
Table 2. Comparison of Mean Difference of Score Of Different Variables in NDPS and BQN Questionnaires Between Two Study Groups Before and After the Intervention

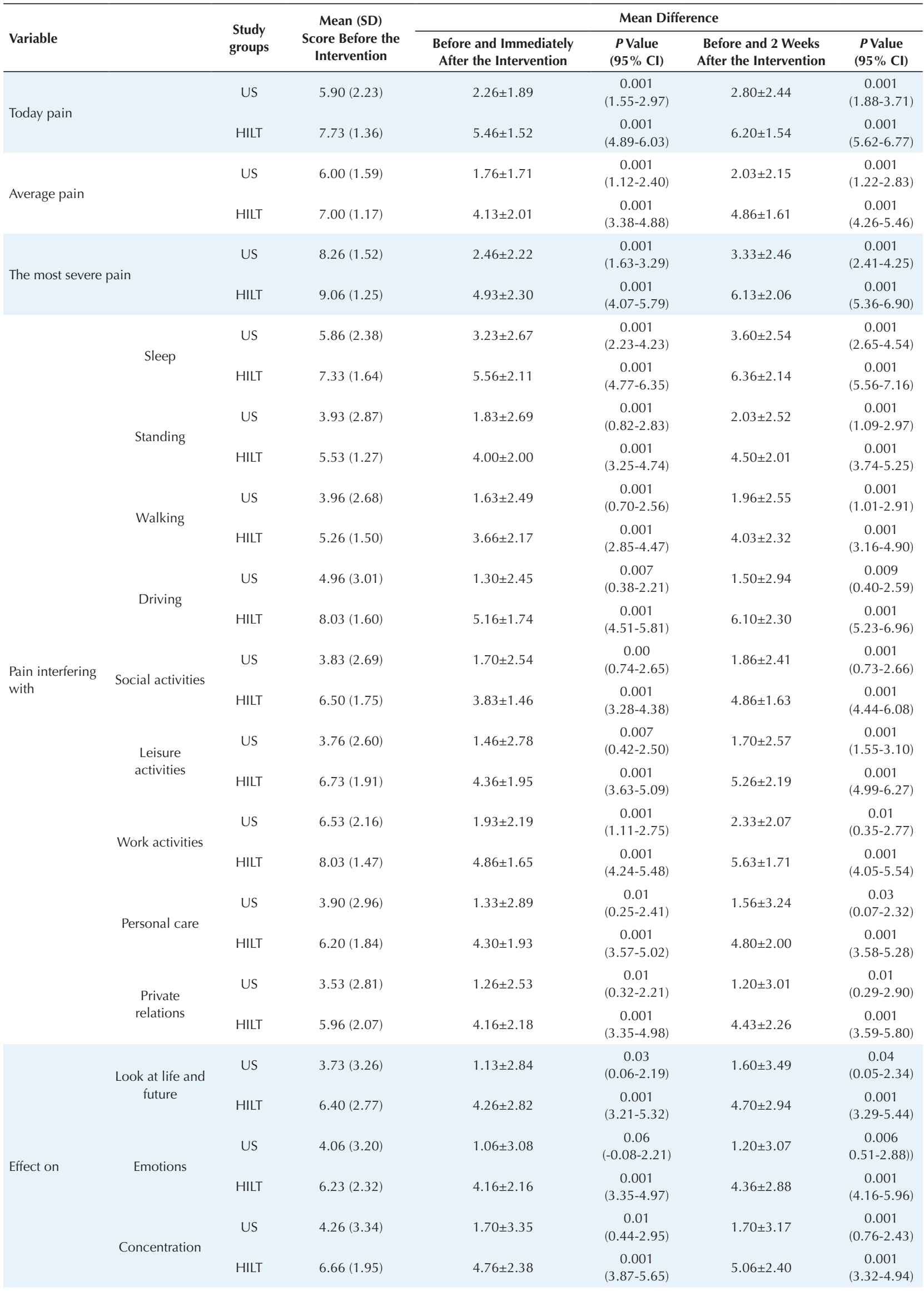




\begin{tabular}{|c|c|c|c|c|c|c|}
\hline \multirow{2}{*}{ Neck stiffness } & US & $4.10(2.98)$ & $1.10 \pm 1.86$ & $\begin{array}{c}0.003 \\
(0.40-1.79)\end{array}$ & $1.60 \pm 2.23$ & $\begin{array}{c}0.004 \\
(0.53-2.46)\end{array}$ \\
\hline & HILT & $5.46(2.38)$ & $3.96 \pm 2.10$ & $\begin{array}{c}0.001 \\
(3.17-4.75)\end{array}$ & $4.13 \pm 2.17$ & $\begin{array}{c}0.001 \\
(3.94-5.79)\end{array}$ \\
\hline \multirow{2}{*}{ Difficulty in head movement } & US & $4.80(2.48)$ & $1.56 \pm 2.41$ & $\begin{array}{c}0.001 \\
(0.66-2.46)\end{array}$ & $1.50 \pm 2.59$ & $\begin{array}{c}0.004 \\
(0.56-2.70)\end{array}$ \\
\hline & HILT & $6.26(2.09)$ & $4.53 \pm 2.52$ & $\begin{array}{c}0.001 \\
(3.58-5.47)\end{array}$ & $4.86 \pm 2.47$ & $\begin{array}{c}0.001 \\
(3.55-5.24)\end{array}$ \\
\hline \multirow{2}{*}{$\begin{array}{l}\text { Difficulty in upward- and } \\
\text { downward-looking }\end{array}$} & US & $4.70(3.08)$ & $1.13 \pm 2.14$ & $\begin{array}{c}0.007 \\
(0.33-1.93)\end{array}$ & $1.63 \pm 2.85$ & $\begin{array}{c}0.01 \\
(0.43-2.83)\end{array}$ \\
\hline & HILT & $6.36(2.00)$ & $4.10 \pm 2.27$ & $\begin{array}{c}0.001 \\
(3.24-4.95)\end{array}$ & $4.40 \pm 2.25$ & $\begin{array}{c}0.001 \\
(4.30-5.82)\end{array}$ \\
\hline \multirow{2}{*}{ Difficulty in working above head } & US & $4.60(3.13)$ & $1.30 \pm 2.73$ & $\begin{array}{c}0.014 \\
(0.28-2.31)\end{array}$ & $1.63 \pm 3.22$ & $\begin{array}{c}0.001 \\
(0.99-3.74)\end{array}$ \\
\hline & HILT & $6.73(1.63)$ & $4.46 \pm 2.33$ & $\begin{array}{c}0.001 \\
(3.59-5.33)\end{array}$ & $5.06 \pm 2.03$ & $\begin{array}{c}0.001 \\
(4.05-5.61)\end{array}$ \\
\hline \multirow{2}{*}{ Pain-relieving with analgesic } & US & $3.86(3.18)$ & $1.53 \pm 3.38$ & $\begin{array}{c}0.019 \\
(0.27-2.79)\end{array}$ & $2.36 \pm 3.68$ & $\begin{array}{c}0.001 \\
(1.91-3.81)\end{array}$ \\
\hline & HILT & $5.76(2.20)$ & $4.40 \pm 2.72$ & $\begin{array}{c}0.001 \\
(3.38-5.41)\end{array}$ & $4.83 \pm 2.08$ & $\begin{array}{c}0.001 \\
(4.35-5.57)\end{array}$ \\
\hline \multirow{2}{*}{ Mean score of neck pain } & US & $6.40(1.99)$ & $2.36 \pm 1.84$ & $\begin{array}{c}0.001 \\
(1.04-2.75)\end{array}$ & $2.86 \pm 2.54$ & $\begin{array}{c}0.001 \\
(1.85-3.74)\end{array}$ \\
\hline & HILT & $7.06(1.70)$ & $4.50 \pm 2.16$ & $\begin{array}{c}0.001 \\
(3.85-5.14)\end{array}$ & $4.96 \pm 1.62$ & $\begin{array}{c}0.001 \\
(4.82-6.04)\end{array}$ \\
\hline \multirow{2}{*}{ Anxiety } & US & $6.33(1.86)$ & $0.96 \pm 3.73$ & $\begin{array}{c}0.16 \\
(-0.42-2.36)\end{array}$ & $2.20 \pm 4.29$ & $\begin{array}{c}0.001 \\
(1.08-2.98)\end{array}$ \\
\hline & HILT & $7.33(1.37)$ & $4.73 \pm 2.40$ & $\begin{array}{c}0.001 \\
(3.83-5.63)\end{array}$ & $4.60 \pm 2.84$ & $\begin{array}{c}0.001 \\
(4.32-5.47)\end{array}$ \\
\hline \multirow{2}{*}{ Depression } & US & $4.76(2.23)$ & $1.00 \pm 2.71$ & $\begin{array}{c}0.053 \\
(-0.01-2.01)\end{array}$ & $1.76 \pm 3.08$ & $\begin{array}{c}0.009 \\
(0.59-3.80)\end{array}$ \\
\hline & HILT & $6.63(1.58)$ & $4.23 \pm 2.52$ & $\begin{array}{c}0.001 \\
(3.28-5.17)\end{array}$ & $4.30 \pm 2.92$ & $\begin{array}{c}0.001 \\
(3.53-5.66)\end{array}$ \\
\hline \multirow{2}{*}{$\begin{array}{l}\text { Effect on working indoors or } \\
\text { outdoors }\end{array}$} & US & $6.83(1.91)$ & $2.53 \pm 2.30$ & $\begin{array}{c}0.001 \\
(1.67-3.39)\end{array}$ & $2.80 \pm 2.23$ & $\begin{array}{c}0.004 \\
(0.61-2.91)\end{array}$ \\
\hline & HILT & $7.60(1.69)$ & $4.76 \pm 2.48$ & $\begin{array}{c}0.001 \\
(3.83-5.69)\end{array}$ & $5.10 \pm 2.21$ & $\begin{array}{c}0.001 \\
(3.20-5.39)\end{array}$ \\
\hline \multirow{2}{*}{ Ability to control pain } & US & $4.76(3.24)$ & $2.36 \pm 3.88$ & $\begin{array}{c}0.002 \\
(0.91-3.81)\end{array}$ & $3.10 \pm 4.04$ & $\begin{array}{c}0.001 \\
(1.96-3.63)\end{array}$ \\
\hline & HILT & $6.23(1.95)$ & $5.00 \pm 2.49$ & $\begin{array}{c}0.001 \\
(4.06-5.93)\end{array}$ & $5.23 \pm 1.92$ & $\begin{array}{c}0.001 \\
(4.27-5.92)\end{array}$ \\
\hline
\end{tabular}

higher than US.

\section{Ethical Considerations}

This study was a thesis for receiving a master of occupational health and was approved by the ethics committee of Shahid Sadoughi University of Medical Sciences (Ethics Code: IR.SSU.SPH.REC.1398.058) and was registered in Iranian registry of clinical trials (identifier: IRCT20190505043483N1; https://en.irct.ir/ trial/39360).

\section{Conflict of Interests}

The authors declare that they have no conflict of interest.

\section{References}

1. Saatchian A, Khoshraftar Yazdi N, Zareie Kheybari S, Qaderi Jagharg H. Comparison of the effect of shorttime massage using neuromuscular facilitation exercises
(NFE) on neck and shoulder pain among employees with myofascial trigger points in the trapezoid muscle. Occup Med. 2016;8(1):43-53. doi: 10.22089/SMJ.2021.9503.1444. [In Persian]

2. Saadat M, Shaterzadeh Yazdi M, Arastoo A, Zahednegad S, Negahban Seuki H, Bigdeli A. Indicators of changes in postural stability with chronic nonspecific neck pain. Jundishapur J Health Sci. 2012;11(3):277-83. [In Persian].

3. Falla D, Jull G, Edwards S, Koh K, Rainoldi A. Neuromuscular efficiency of the sternocleidomastoid and anterior scalene muscles in patients with chronic neck pain. Disabil Rehabil. 2004;26(12):712-7. doi: 10.1080/09638280410001704287.

4. Jafari Rodbandi A, Karimi A, Mardi H, Nadri F, Nadri H. The Prevalence of musculoskeletal disorders and posture assessment by ART method in mosaic art in Kerman city. $J$ Neyshabur Univ Med Sci. 2014;2(2):38-42.

5. Barry M, Jenner J. ABC of rheumatology: pain in neck, shoulder, and arm. BMJ. 1995; 310(6973):183-6. doi: 10.1136/bmj.310.6973.183. 
6. Leclerc A, Niedhammer I, Landre M-F, Ozguler A, Etore P, Pietri-Taleb F. One-year predictive factors for various aspects of neck disorders. Spine. 1999; 24(14): 1455-1462. doi: 10.1097/00007632-199907150-00011.

7. Cohen SP, Gallagher RM, Davis SA, Griffith SR, Carragee EJ. Spine-area pain in military personnel: a review of epidemiology, etiology, diagnosis, and treatment. Spine. 2012; 12(9):833-42. doi:10.1016/j.spinee.2011.10.010.

8. Côté P, Cassidy JD, Carroll L. The factors associated with neck pain and its related disability in the Saskatchewan population. Spine. 2000; 25(9):1109-17. doi: 10.1097/00007632-200005010-00012.

9. Mäntyselkä PT, Kumpusalo EA, Ahonen RS, Takala JK. Direct and indirect costs of managing patients with musculoskeletal pain-challenge for health care. Europ J Pain. 2002; 6(2):141-8. doi: 10.1053/eujp.2001.0311.

10. Ylinen J, Takala E-P, Nykänen M, Häkkinen A, Mälkiä E, Pohjolainen T, et al. Active neck muscle training in the treatment of chronic neck pain in women: a randomized controlled trial. JAMA. 2003; 289 (19): 2509-2516. doi: 10.1001/jama.289.19.2509.

11. Seo B-K, Lee J-H, Kim P-K, Baek Y-H, Jo D-J, Lee S. Bee venom acupuncture, NSAIDs or combined treatment for chronic neck pain: study protocol for a randomized, assessor-blind trial. Trials. 2014; 15(1):132. doi: 10.1186/1745-6215-15-132.

12. Bakar Y, Sertel M, Öztürk A, Yümin ET, Tatarli N, Ankarali H. Short term effects of classic massage compared to connective tissue massage on pressure pain threshold and muscle relaxation response in women with chronic neck pain: a preliminary study. J Manip Physiol Ther. 2014;37(6):415-21. doi: 10.1016/j.jmpt.2014.05.004.

13. Alayat MSM, Mohamed AA, Helal OF, Khaled OA. Efficacy of high-intensity laser therapy in the treatment of chronic neck pain: a randomized double-blind placebo-control trial. Lasers Med Sci. 2016;31(4):687-94. doi: 10.1007/ s10103-016-1910-2.

14. Matijević-Mikelić V, Crnković M, Matijević M, Leović D, Demarin V. The effectiveness of the therapeutic ultrasound on the psycho-physiological functioning in patients who presented with neck pain. Coll Antropol. 2012; 6(3): 921928.

15. Taimela S, Takala E-P, Asklöf T, Seppälä K, Parviainen S. Active treatment of chronic neck pain: a prospective randomized intervention. Spine. 2000; 25(8):1021-7. doi: 10.1097/00007632-200004150-00018.

16. Alayat MSM, Aly THA, Elsayed AEM, Fadil ASM. Efficacy of pulsed Nd: YAG laser in the treatment of patients with knee osteoarthritis: a randomized controlled trial. Lasers Med Sci. 2017;32(3):503-11. doi: 10.1007/s10103-0172141-x.

17. Monici M, Cialdai F, Fusi F, Romano G, Pratesi R. Effects of pulsed Nd:YAG laser at molecular and cellular level. A study on the basis of Hilterapia. Energy for Health. 2008;3:26-33.

18. Peplow PV, Chung T-Y, Baxter GD. Application of low level laser technologies for pain relief and wound healing: overview of scientific bases. Phys Ther Rev. 2010; 15(4): 253-285. doi: 10.1179/1743288X10Y.0000000008.

19. Hagiwara S, Iwasaka H, Hasegawa A, Noguchi T. Preirradiation of blood by gallium aluminum arsenide (830 $\mathrm{nm}$ ) low-level laser enhances peripheral endogenous opioid analgesia in rats. Anesth Analg. 2008;107(3):105863. doi: 10.1213/ane.0b013e31817ee43e.

20. Ezzati K, Laakso E, Hasannnejad A, Fekrazad R, Aris A. The beneficial effects od high-intensity laser therapy and co-interventions on musculoskeletal pain management: a systematic review. J lasers Med Sci. 2020; 11(1): 81-90.

21. Waling K, Sundelin G, Ahlgren C, Järvholm B. Perceived pain before and after three exercise programs-a controlled clinical trial of women with work-related trapezius myalgia. Pain. 2000;85(1-2):201-7. doi: 10.1016/S03043959(99)00265-1.

22. Kim E-D, Won YH, Park S-H, Seo J-H, Kim D-S, Ko $\mathrm{M}-\mathrm{H}$, et al. Efficacy and Safety of a Stimulator Using Low-Intensity Pulsed Ultrasound Combined with Transcutaneous Electrical Nerve Stimulation in Patients with Painful Knee Osteoarthritis. Pain Res Manag. 2019; 5: 1-10. doi: 10.1155/2019/7964897.

23. Nazari A, Moezy A, Nejati P, Mazaherinezhad A. Efficacy of high-intensity laser therapy in comparison with conventional physiotherapy and exercise therapy on pain and function of patients with knee osteoarthritis: a randomized controlled trial with 12-week follow up. Laser Med Sci. 2019;34(3):505-16. doi: 10.1007/s10103-0182624-4.

24. Best N, Loppar A, Derlien S, Ullrich S, Smolenski U. The effectiveness of ultrasound applications in comparison to high-intensity laser regarding to the outcome measure of pain intensity at patients with disorders of the lumbar spine or the shoulder. Phys Med Rehab Kuror. 2012; 22(3): 15461. doi: 10.1055/s-0032-1309024.

25. Fiore P, Panza F, Cassatella G, Russo A, Frisardi V, Solfrizzi $\mathrm{V}$, et al. Short-term effects of high-intensity laser therapy versus ultrasound therapy in the treatment of low back pain: a randomized controlled trial. Eur J Phys Rehabil Med. 2011;47(3):367-73.

26. Santamato A, Solfrizzi V, Panza F, Tondi G, Frisardi V, Leggin BG, et al. Short-term effects of high-intensity laser therapy versus ultrasound therapy in the treatment of people with subacromial impingement syndrome: a randomized clinical trial. Phys Ther. 2009; 89(7):643-52. doi: 10.2522/ptj.20080139.

27. Boyraz I, Yildiz A, Koc B, Sarman H. Comparison of highintensity laser therapy and ultrasound treatment in the patients with lumbar discopathy. BioMed Res Int. 2015; ArticID 304328, 6 pages. doi: 10.1155/2015/304328.

28. Kolu E, Buyukavci R, Akturk S, Eren F, Ersoy Y. Comparison of high-intensity laser therapy and combination of transcutaneous nerve stimulation and ultrasound treatment in patients with chronic lumbar radiculopathy: A randomized single-blind study. Pak J Med Sci. 2018;34(3):530-534. doi: 10.12669/pjms.343.14345.

29. Akbari A, Ghiasi F, Barahoie M, Arab-Kangan M. The comparison of effectiveness of muscles specific stabilization training and dynamic exercises on the chronic neck pain and disability. J Gorgan Univ Med Sci. 2010;11(4):29-112.

30. Ferreira ML, Borges BM, Rezende IL, Carvalho LP, Soares LP, Dabes RAI, et al. Are neck pain scales and questionnaires compatible with the international classification of functioning, disability and health? A systematic review. Disabil Rehabil. 2010;32(19):1539-46. doi: 10.3109/09638281003611045. 
31. Melzack R. The short-form McGill pain questionnaire. Pain 1987; 30(2):191-7. doi: 10.1016/0304-3959(87)910748.

32. Bolton JE, Humphreys BK. The Bournemouth Questionnaire: a short-form comprehensive outcome measure. II. Psychometric properties in neck pain patients. J Manip Physiol Ther. 2002; 25(3):141-8. doi: 10.1067/ mmt.2002.123333.

33. Vernon H, Mior S. The Neck Disability Index: a study of reliability and validity. J Manip Physiol Ther. 1991; 14(7):409-15. doi: 10.1007/978-94-007-0753-5_1915. 220.

34. Foroutani H, Nakhostin Ansari N, Naghdi S, Jalei Sh. Investigating the responsiveness of the Persian version of functional rating index in patients with chronic nonspecific neck pain: brief report. Tehran Univ Med J. 2018; 76(7): 498-502.

35. Srbely JZ, Dickey JP, Lowerison M, Edwards AM, Nolet
PS, Wong LL. Stimulation of myofascial trigger points with ultrasound induces segmental antinociceptive effects: a randomized controlled study. Pain. 2008; 139(2): 260-6. doi: 10.1016/j.pain.2008.04.009.

36. Zati A, Valent A. Physical therapy: new technologies in rehabilitation medicine. Edizioni Minerva Medica. 2006; 2006:162-85. doi: 10.1155/2020/1350281.

37. Chow R, Armati P, Laakso EL, Bjordal JM, Baxter GD. Inhibitory effects of laser irradiation on peripheral mammalian nerves and relevance to analgesic effects: a systematic review. Photomed Laser Surg. 2011; 29(6):36581. doi: 10.1089/pho.2010.2928.

38. Kujawa J, Zavodnik L, Zavodnik I, Buko V, Lapshyna A, Bryszewska M. Effect of low-intensity $(3.75-25 \mathrm{~J} / \mathrm{cm} 2)$ nearinfrared $(810 \mathrm{~nm})$ laser radiation on red blood cell ATPase activities and membrane structure. J Clin Laser Med Surg. 2004; 22(2):111-7. doi: 10.1089/104454704774076163. 